\title{
Nós, os ex-liberais
} We, ex-liberals

Patrícia Fernandes* Universidade da Beira Interior

Universidade do Minho patriciafernandes@protonmail.com

doi: $x x x x x x x x x x x$

\begin{tabular}{|c|c|c|}
\hline Recebido / Received & Aceite / Accepted & Publicado / Published \\
31.07 .2020 & 1.09 .2020 & 1.06 .2021 \\
\hline
\end{tabular}

Como citar este capítulo / How to quote this chapter:

Fernandes, P. (2021). "Nós, os ex-liberais". In Reis, B., Um mundo de incertezas; as leituras possíveis de um tempo pandémico (pp. 149-168). Lisboa: NIP-C@M \& UAL, disponível em $\underline{x x x x x x x x}$. DOI xxxxxxx.

\footnotetext{
* Praxis- Universidade da Beira Interior
} 
"É inútil discutir com os republicanos. Não compreendem que procurar restabelecer a República na época atual é como pretender, por exemplo, impor às mulheres e maridos modernos os preceitos da antiga castidade. É o mesmo que tenta recuar a sombra de um ponteiro num quadrante solar: não se pode, eis tudo".

Robert Graves, Eu, Cládio Imperador

\section{Introdução}

O presente texto visa contribuir para a reflexão sobre os impactos políticos que resultarão da COVID-19, tendo em consideração o contexto mais geral que vem marcando a situação política ocidental nas últimas décadas. A partir de uma perspetiva filosófica, convocaremos ferramentas que nos permitam incidir alguma luz sobre estes impactos e contribuir para uma melhor reflexão dos desafios atuais. Para esse efeito, partiremos da descrição do liberalismo como o paradigma filosófico e político que se tornou hegemónico após as revoluções liberais e que molda a nossa forma de ver o mundo. É a partir deste paradigma liberal que ganhará forma o regime de democracia liberal que proliferou pelo mundo ao longo do século XX.

A nossa hipótese de trabalho é a de que as décadas mais recentes têm assistido a um corroer dos pilares do paradigma liberal, traduzindo-se numa crise de democracia liberal. Tentaremos identificar os principais sintomas dessa crise, considerando a situação pandémica atual como um fator fundamental para o seu aprofundamento. Será dada especial atenção à dimensão 
tecnológica: se a tecnologia digital e algorítmica é um dos fatores principais de desgaste dos princípios liberais, ela também se mostra particularmente relevante na análise a que nos propomos, se atendermos às reações que foram apresentadas como resposta à COVID-19.

Embora a proximidade aos acontecimentos não nos permita retirar ilações definitivas, é possível, ainda assim, e adivinhando os impactos futuros nas sociedades e economias ocidentais, afirmar que a pandemia pode ter acelerado o caminho para um regime que se tem popularizado como "democracia iliberal". É esta hipótese de trabalho que procuraremos apresentar de seguida, começando por clarificar a utilização do conceito "paradigma liberal".

\section{O paradigma liberal}

Em 1956, W. B. Gallie cunhou a expressão "conceito essencialmente contestado" para se referir aos termos sobre os quais não é possível chegar a consenso quanto ao seu sentido ou concretização, usando como exemplo as noções de arte, doutrina cristã ou democracia. De facto, o termo democracia pode convocar diferentes entendimentos e aplicações, devendo obrigar ao rigor de não confundir democracia dos antigos e democracia dos modernos ou os diferentes entendimentos da democracia moderna, como "democracia representativa", "democracia participativa", "democracia deliberativa" ou "verdadeira democracia". Estas expressões podem convocar correntes político-filosóficas, 
como as de democracia deliberativa que foram desenvolvidas nas últimas décadas do século $X X$, ou referirem-se a movimentos políticos específicos, como as exigências de verdadeira democracia que se seguiram à crise económico-financeira de 2007/8. Considerando a nossa proposta de refletir sobre os impactos da COVID-19 nos regimes democráticos ocidentais, importará, portanto, clarificar o que pretendemos dizer com o termo "democracia" no presente texto.

Por sistemas democráticos ocidentais referimo-nos às democracias liberais, que foram sendo forjadas nos últimos 250 anos e que correspondem ao regime político que saiu vitorioso da proclamação do fim da História por Francis Fukuyama (1992). Esse regime político resulta de um enquadramento filosófico que designaremos por paradigma liberal ou, para usar a formulação de Richard Rorty, Liberalismo-com-letra-maiúscula ${ }^{1}$. Compreender a crise da democracia liberal e os impactos da pandemia para o agravamento dessa crise implica reconhecermos este paradigma liberal e fazer um exercício de distanciamento para observarmos o atual momento político com uma certa distância histórica e filosófica.

O paradigma liberal começou a ser concebido ao longo do século XVII, em especial em Inglaterra, como resposta aos regimes absolutistas que caraterizavam os Estados modernos da altura, mas as suas raízes podem ser encontradas nas reivindicações de autonomia e autogoverno das cidades italianas do Renascimen-

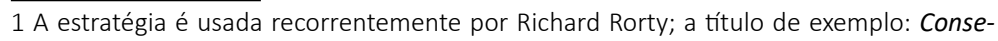
quences of Pragmatism (1982). 
to, pelo que estão intimamente ligadas ao surgimento da burguesia, das dinâmicas económicas capitalistas e das chamadas liberdades burguesas. Será, no entanto, com John Locke e o seu Segundo Tratado sobre o Governo Civil (2006) que surgirá uma formulação amadurecida do espírito liberal, centrado no primado do indivíduo, anterior à comunidade e dotado de direitos naturais que constituem limites à atividade do Estado. Esse indivíduo, provido de razão e autonomia, constitui voluntariamente o Estado através do seu consentimento que tem como fim garantir as liberdades individuais, baseando-se na lei e na lógica de divisão de poderes. Contra o poder arbitrário do monarca absoluto, surge o Estado de Direito como garantia da liberdade individual.

A maioria destas noções seria aprofundada por aquilo que consideramos a tradição filosófica liberal que marca o século XVIII e o espírito das Luzes e se traduzirá nas duas revoluções liberais que se seguiram à Revolução Gloriosa a que Locke assistiu: a norte-americana de 1776 e a francesa de 1789. As declarações de direitos, o valor da liberdade e o espírito universal seriam as bandeiras destas revoluções que constituiriam o paradigma a partir do qual nasceram as atuais sociedades globalizadas. $\mathrm{E}$ estas pretendem-se emancipadas de tudo o que constitui limites ou grilhões ao sujeito de Razão: tradições, passado e dogmas, quer religiosos quer filosóficos -, tudo cairia no caminho do Progresso.

Acompanhava este espírito de liberdade política, uma ânsia de liberdade ainda maior: face ao espírito empírico do renascimento 
e às revoluções científicas da primeira modernidade, o século das Luzes e da Razão seria também o século da Ciência por excelência. A Ciência seria a ferramenta que permitiria aceder à Verdade-com-letra-maiúscula e concretizar a última libertação humana: a libertação da natureza. De facto, o espírito da modernidade empreende a luta contra a natureza, que Francis Bacon tão bem formula no seu Novum Organum, de 1620. 0 facto de determos pela primeira vez as ferramentas capazes de controlar a natureza e conhecer todos os seus segredos fez vingar a esperança de que, por fim, nos pudéssemos emancipar das condições biológicas e superar as dificuldades que tinham marcado a existência humana até então. Tal revelar-se-ia a mais perigosa de todas as ilusões de controlo.

\section{A crise da democracia liberal}

Se procurássemos uma palavra capaz de representar o espírito da modernidade talvez a mais acertada fosse precisamente a de "controlo". A ânsia de liberdade e autonomia que carateriza a modernidade visa fazer o homem acreditar que é ele que dispõe do controlo sobre a sua vida, que não se encontra nem nas mãos da natureza nem nas mãos de qualquer outra autoridade, humana ou divina. O próprio regime político moderno - o de democracia liberal -, representa essa ânsia de controlo pelo destino político do país, a sensação de que tomamos parte do processo de decisão das nossas vidas, presentes e futuras. Concentremos, então, a nossa atenção neste específico regime político. 
Tal como foi traçado, o paradigma liberal assenta, politicamente, num dispositivo intelectual que ocupa um lugar central nas nossas reflexões políticas: o contrato social, que permite conciliar o primado do indivíduo com a instituição do poder político e sua legitimidade. Ao fazê-lo, este dispositivo abre a porta para a ideia de soberania popular que os modelos políticos anteriores tinham recusado. De facto, a ideia de que a legitimidade política reside nos indivíduos conduzirá a recuperar o conceito antigo de democracia. Importa, contudo, reconhecer que a associação não foi imediata. Na verdade, a ideia de democracia despertava profundo receio, e algum horror, nos intelectuais oitocentistas. Os iluministas do século XVIII não olhavam para a democracia grega ou os governos populares de Roma com o olhar romantizado que ainda é recorrente entre nós. Pelo contrário, temiam a instabilidade política do governo da maioria, a irracionalidade das massas, a decisão arbitrária, a ameaça que a participação política implica para a liberdade individual.

Mas os Founding Fathers norte-americanos viram-se rapidamente confrontados com o dilema de dar forma à sua nova República, que resultava de uma guerra feita por muitos homens vulgares e iletrados, mas que mereciam o direito a participar politicamente nos novos estados independentes que tinham ajudado a fundar. Terá sido Alexander Hamilton a usar pela primeira vez, em 1777, a expressão "democracia representativa" e nos anos seguintes formulou-se teoricamente um sistema que permitiria conciliar os valores da soberania popular com os 
receios decorrentes das experiências da Antiguidade 2 . Com a ideia de representação estava encontrado o mecanismo que permitiria, nas décadas subsequentes, atualizar o regime democrático ou popular dos antigos para as novas exigências modernas de liberdade individual, como chamava a atenção Benjamin Constant no seu discurso de 1819.

A ideia de representação era estranha aos antigos, mas a democracia moderna dava mais um passo com a limitação da própria vontade democrática através da instituição de declarações de direitos nos novos estados constitucionais. Consagra-se, assim, a ideia de limitação do poder político, como John Stuart Mill argumenta (2006), com uma soberania popular assente em eleições periódicas.

Este desenho institucional significa que a legitimidade política dos regimes de democracia liberal não se encontra exatamente no consentimento, explícito ou tácito, da maioria da população, mas no respeito por uma série de regras institucionais que garantem a separação de poderes, a regularidade da atuação do governo, a liberdade de expressão e manifestação e o respeito pelos direitos individuais. O Parlamento surge, neste sentido, como património civilizacional moderno por excelência: é o local onde, substituindo a força e a violência pela troca de argumentos, a discussão e o controlo políticos decorrem de acordo com regras e princípios pré-estabelecidos.

2 Cf. entrevista a Nadia Urbinati e Bernard Manin, na qual estes aspetos são discutidos. Landemore, H. (2008). "Is representative democracy really democratic? Interview of Bernard Manin and Nadia Urbinati". La vie des idées. 
É este conceito de "democracia" que se vai popularizar ao longo do século $X I X^{3}$, mas podemos indicar o final da primeira guerra mundial e o projeto do presidente norte-americano Woodrow Wilson como o momento em que os regimes de democracia liberal se foram implementando pela Europa, despertando, em alguns países, reações que conduziram à segunda guerra mundial. Mas a vitória dos Aliados permitiu a consolidação progressiva da democracia representativa na maioria dos países europeus, acompanhando o sucesso económico dos Trinta Gloriosos Anos.

É possível, no entanto, registar, desde as últimas décadas do século XX, manifestações consistentes de crise. Como afirmam James D. Hunter e John Owen IV:

\begin{abstract}
“Os sintomas desta doença são facilmente observáveis: um enviesamento cada vez mais acentuado na distribuição da riqueza; o declínio das instituições tradicionais, desde as associações cívicas até aos sindicatos e à família; a perda de confiança na autoridade - política, religiosa, científica, jornalística - e entre os próprios cidadãos; a desilusão cada vez maior com o progresso na atribuição de justiça igual para todos; acima de tudo, talvez, a polarização persistente e crescente entre aqueles que querem sociedades cada vez mais abertas e experimentais e os que querem conservar as várias instituições e práticas tradicionais" (Hunter \& Owen IV, 2019: 9).
\end{abstract}

3 Recordemos aqui a importância da obra publicada, em 1835 e 1840, por Alexis de Tocqueville para esse processo de divulgação na Europa: Da Democracia na América. 
Esta doença é particularmente evidente no que diz respeito aos elementos que mais simbolizam a democracia liberal: a participação eleitoral foi-se reduzindo progressivamente e o sentimento de desconfiança e falta de representação em relação ao Parlamento aumentou na mesma medida. De facto, as últimas décadas revelaram um curioso paradoxo: à medida que as sociedades se tornaram mais igualitárias, e fomos abandonando as regras de deferência que caraterizaram os tempos anteriores, fomos perdendo a confiança nos nossos representantes. Os deputados deixaram de constituir uma elite que se apresentava como intelectual e moralmente superior (pensemos no espírito de representação personalizado por Edmund Burke) e passaram a ser percecionados como pessoas comuns - pessoas-como-nós -, e, portanto, detendo os mesmos defeitos morais e intelectuais dos nossos amigos, suscetíveis das mesmas críticas e desconfiança que dedicamos aos nossos vizinhos. Como veremos, a tecnologia digital viria a agravar esta situação, levantando a hipótese de saber se sociedades igualitárias são compatíveis com o espírito da representação.

A crise iniciada no setor financeiro dos Estados Unidos em 2007/8 e que se alastrou por todo o mundo (com uma incidência particularmente gravosa na Europa e a sua transmutação em crise das dívidas soberanas) constituiu um fator crucial dos desenvolvimentos mais recentes. A perceção de uma resposta inadequada e injusta à crise, espoletou sentimentos de desconfiança crescente em relação ao sistema político e a resposta das populações tem sido a de radicalizar as suas posições, esvaziando 
o centro. Os movimentos populistas, na medida em que fazem uma crítica direta à representação e apresentam um líder forte como forma de estabelecer uma relação imediata com as populações, têm crescido em quase todos os países. E aqueles que optaram pela introdução de mecanismos com vista a re-legitimar o processo democrático - como aconteceu no Reino Unido com a convocação do referendo sobre o Brexit -, não obtiveram êxito: ao invés de aproximar os cidadãos do processo político, essas soluções têm aprofundado a divisão social e aumentado a polarização política.

O sucesso de alguns líderes fortes - em especial, Viktor Orbán na Hungria, Vladimir Putin na Rússia e Recep Erdoğan na Turquia -, tem popularizado uma expressão cunhada pelo jornalista Fareed Zakaria em 1997: parecemos estar a assistir ao crescimento de democracias iliberais. Estes são regimes que se afirmam como democracias formais, assentando na decisão da maioria, mas que recusam os princípios liberais que decorrem historicamente do paradigma liberal. Singularmente, autores como Roberto Stefan Foa e Yascha Mounk (2016) têm mostrado como esse afastamento da democracia liberal e uma aproximação a valores iliberais está cada vez mais presente nos jovens.

A COVID-19, não tendo iniciado a crise do paradigma liberal e a subsequente crise da democracia liberal, tornou todos estes fatores mais evidentes, como vários analistas políticos têm destacado, sobretudo com declarações de estado de emergência

4 Foreign Affairs, novembro/dezembro de 1997, "The Rise of Illiberal Democracy". 
e adiamentos de eleições. Mas a melhor imagem dessa evidência no contexto europeu talvez seja a atitude provocatória de Orbán, que aproveitou a crise para projetar uma imagem de fortalecimento do seu poder e com isso passar uma mensagem de iliberalismo crescente. Ivan Krastev formula especialmente bem a questão quando afirma:

\begin{abstract}
“Por que motivo sentiu Orbán necessidade de usurpar poderes que já possuía? Afirmar que a COVID-19 Foi, para ele, uma maneira de fomentar um golpe de Estado é uma explicação simplista e inútil. Considero muito mais importante o facto de Orbán utilizar a crise para mostrar a Bruxelas que pode infringir as regras da União Europeia com impunidade" (Krastev, 2020: 62).
\end{abstract}

Por outro lado, os efeitos económicos e sociais da COVID-19 podem reforçar aquela aproximação dos mais jovens às propostas iliberais. Embora as consequências físicas da doença sejam mais perigosas para os idosos do que para os mais novos, as consequências económicas e sociais afetarão muito mais gravemente os jovens, incidindo novamente sobre as gerações mais atingidas pela crise económico-financeira anterior. Num mundo cada vez mais tecnológico, o futuro liberal não se revela promissor.

\title{
A sociedade tecnológica
}

Quando, em 1995, Theodore Kaczynski conseguiu a publicação do seu manifesto sobre a sociedade industrial e as suas 
consequências (ISAIF), muito inspirado no trabalho de Jacques Ellul ${ }^{5}$, deu a conhecer um dos argumentos mais interessantes sobre o impacto da tecnologia nas nossas vidas. De acordo com Kaczynski, a tecnologia implica sempre a perda de liberdade humana - o mesmo é dizer, da dignidade humana -, mesmo quando se apresenta como dispositivo de liberdade (Kaczynski, 2010). O exemplo usado é o do automóvel: exposto inicialmente como modo de expansão de liberdade individual, revelou-se, gradualmente, como cativeiro dos nossos movimentos e da nossa possibilidade de movimento. $O$ exemplo pode ser facilmente atualizado para o telemóvel, mais revelador das nossas dependências do que das nossas liberdades.

O argumento tem um cariz filosófico mais forte quando é aplicado à tecnologia algorítmica que tem marcado a nossa vida nos últimos anos, na medida em que esta atinge de forma muito particular o pilar ideológico fundamental do liberalismo: a ideia de que somos seres livres. O funcionamento do algoritmo assenta na acumulação de dados e informações sobre nós por forma a conseguir controlo sobre as nossas vontades, os nossos pensamentos e as nossas ações (Harari, 2017). É já um cliché dizer que o algoritmo nos conhece melhor do que nós mesmos e os usos que tal realidade possibilita são imensos, desde a venda dos nossos dados a empresas comerciais até ao controlo político, como a polémica em torno das eleições norte-americanas e brasileiras comprova.

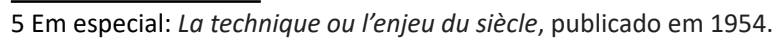


Não é, contudo, apenas este o pilar destruído pela tecnologia digital. Em particular, as redes sociais por ela oferecidas têm destruído a ideia de Verdade-com-letra-maiúscula, promovendo a radicalização do discurso e a polarização da sociedade, cada vez mais organizada em torno de bolhas sociais, que constituem as tribos políticas ou identitárias. Mas promove um ataque igualmente feroz ao mecanismo de representação. Como ByungChul Han (2016) chama a atenção, ao eliminar as distâncias e permitir aproximar as pessoas do poder, a tecnologia digital torna a ideia de representação obsoleta e fragiliza a estrutura fundamental da democracia liberal.

Simultaneamente, a tecnologia moderna moldou o mundo de uma forma muito específica e que se relaciona intimamente com a questão pandémica: acelerou o tempo e a nossa disponibilidade de espera. Tudo acontece hoje mais rápido e a nossa expetativa é a da imediatez. As repercussões políticas são claras: as populações esperam que as decisões tenham efeitos imediatos, que os governos resolvam rapidamente os problemas, que o dinheiro e o apoio cheguem depressa. Mas o tempo biológico e natural não acompanha o tempo tecnológico mental - há coisas que precisam de tempo e as reações mais imediatas e precipitadas são apenas tentativas de controlar o incontrolável.

A tecnologia, aliás, gira em torno deste paradoxo: prometendo controlo, gera constantemente sensação da falta dele. As sociedades atuais são marcadas pelo sentimento de que o 
tempo, as regras, as exigências, o trabalho, a vida pessoal estão cada vez mais fora do nosso controlo. $\mathrm{E}$ a ansiedade provocada por esta sensação é particularmente hábil a abrir espaço de necessidade para figuras de autoridade e ordem - que são precisamente o cerne das propostas de cariz iliberal.

A verdade é que, apesar de toda emancipação biológica e de todo o controlo prometidos pela tecnologia, a COVID-19 confrontou-nos com as nossas ilusões e os nossos medos. Como diz Ernst Jünger,

\footnotetext{
"todos os horrores com que o mundo é periodicamente inundado não são mais do que um espelho da alma humana, revelada pelo acontecimento. Quantas vezes ouvimos suspirar nos abrigos: "Não é bom que os homens se matem uns aos outros," De facto, queriam dizer: não é bom ser-se morto" (2005: 50).
}

E é este medo da morte que nos pode fazer suspender toda a prudência.

\section{A política da vigilância}

Como vimos, um dos aspetos fundamentais do espírito da modernidade consiste na tentativa de emancipação biológica, o mesmo é dizer libertação dos constrangimentos naturais. As sucessivas revoluções científicas e industriais permitiram solidificar este espírito e esta ambição, mas são, sobretudo, as décadas que se seguem ao final da segunda guerra mundial, 
com os grandes desenvolvimentos ao nível da medicina, da farmacologia e da biomedicina - a chamada "Nova Medicina" -, que dão forma a um modo de vida radicalmente higienizado. Nos países ocidentais, e com exceção de franjas de pobreza extrema, nunca as condições de vida em termos sanitários e de segurança pública foram tão elevadas. Paralelamente, a pacificação crescente do mundo ocidental afastou para os mais recônditos locais da memória, as experiências de vida e de morte que sempre acompanharam a humanidade. Há pouco mais de cem anos, a primeira guerra mundial sujeitava milhões de jovens à experiência brutal das trincheiras. Hoje, ler Jünger significa transportarmo-nos para um mundo radicalmente estranho:

"Vinha primeiro um paralisante segundo de silêncio, quando os olhos se encontravam. Depois soava um grito, abrupto, selvagem, vermelho-sangue, que se gravava nos cérebros como uma marca indelével de ferro em brasa. Este grito arrancava os véus de mundos emocionais tenebrosos e insuspeitos, e forçava todos os que o ouviam a atirarem-se para a frente, para matarem ou para morrerem. As bolas iluminantes flutuavam, trémulas, por cima de um massacre de que nenhum relato pode dar ideia, que não tinha espectadores, salvo aqueles que se esvaziavam de sangue nos cantos sombrios, e cujos olhos exorbitados levavam esta última imagem de caos para as terras do grande silêncio" (Jünger, 2005: 39).

Tudo isto conduziu a uma expetativa crescente de vida sem doenças graves e da mortalidade como acidente ou azar, e 
não como momento inevitável do percurso humano. E os desenvolvimentos ao nível da tecnologia digital e algorítmica criaram a esperança de que, pela primeira vez, poderíamos superar o último grilhão natural: a mortalidade. É, neste sentido, que os transhumanistas defendem a condição de transição da humanidade biológica para uma humanidade tecnológica, que viveria para sempre.

É a partir deste contexto, que Harari designa como o tempo do Homo Deus (2017), que deve ser entendida a reação mundial à pandemia. Apesar de se tratar de uma doença que está longe de revelar índices de mortalidade tão graves como algumas doenças que afligem os países mais pobres, ainda assim espoletou em nós o pânico profundo perante a doença desconhecida, o sofrimento temido e a morte negada. A verdade é que, para lá de todas as promessas de controlo e emancipação da modernidade, aqui estamos, mais uma vez e repetindo a história, perante o incontrolável, o desconhecido, a natureza que também nos tem refém e que faz despertar em nós o atavismo que nos liga ao ser biológico que somos.

Talvez se justifique assim que tenhamos aceitado com tanta facilidade que "[g]overnos benevolentes (e não tão benevolentes) [vigiem] de perto para onde vamos e com quem nos encontramos, determinados a proteger-nos tanto da nossa própria imprudência como da imprudência dos nossos concidadãos" (Krastev, 2020: 8).

A partir de um argumento filosófico próximo do apresentado neste texto, Patrik J. Deneen identifica como um dos fatores de 
crise do liberalismo o facto de este ter substituído a promoção do autogoverno virtuoso dos antigos por uma suposta neutralidade de valores na esfera pública. É sobretudo isto que nos distingue dos antigos. O que resulta deste desconsiderar da educação virtuosa é fazer nascer uma correspondente necessidade de vigilância. Como já não contamos com oautodomínio para exercer a autodisciplina, só nos resta implementar mecanismos de vigilância: "como as normas sociais e de conduta se deterioraram e a ênfase no caráter foi rejeitada como paternalista e opressiva, cada vez mais administrações escolares do país instalam agora câmaras de vigilância nas escolas" (Deneen, 2019: 41).

O liberalismo deu origem a uma cultura de vigilância e monotorização, resultado da falta de partilha de um projeto comum e de confiança em relação aos outros. Passamos, nesse sentido, a tolerar cada vez mais a ideia de que temos de nos sujeitar a modos de vigilância por forma a estarmos seguros. E mesmo que os problemas de violação de privacidade se encontrem amplamente divulgados, com as denúncias, por exemplo, de Edward Snowden, e as polémicas em torno da Cambridge Analytica sejam de conhecimento público, ainda assim milhões de pessoas na Europa têm feito o download de apps de rastreamento e, em Portugal, os estudos revelam que a grande maioria está disposta a utilizá-las ${ }^{6}$.

Deve reconhecer-se que a União Europeia tem revelado especial cuidado com a questão da privacidade, mas o estado

6 Cf. Público, 7 de maio de 2020, "Maioria dos portugueses aceitam app para controlo da covid-19, diz Deco". 
pouco saudável das democracias liberais deveria elevar o nosso grau de alerta. A verdade é que nunca como agora os governos tiveram à sua disposição tanta informação pessoal e todos os mecanismos capazes de exercer controlo e vigilância sobre as nossas vidas. Ainda queremos acreditar que vivemos em democracias liberais, que assentam em regras institucionais previstas nas constituições, mas a verdade é que os princípios liberais parecem estar a tornar-se tão obsoletos hoje como os ideais da república romana durante o governo de Augusto. E se a pandemia não provocou a crise do paradigma liberal, tem ajudado a amplificar os seus fatores, abrindo a porta a um mundo pós-liberal desconhecido.

\section{Bibliografia}

Constant, B. (1985). Da liberdade dos antigos comparada à dos modernos. Revista de Filosofia Política, n.2, pp. 9-25, disponível em: https://www.academia.edu/34737069/DA_LIBERDADE DOS ANTIGOS COMPARADA \%C3\%80 DOS MODERNOS.

Deneen, P. J. (2019). Porque está a falhar o liberalismo?. Lisboa: Gradiva.

Foa, R. S. e Mounk, Y. (2016). The Democratic Disconnect. Journal of Democracy. Vol. 27 - N.o 3, pp. 5-17, available in: http://pscourses. ucsd.edu/ps200b/Foa\%20Mounk\%20Democratic\%20Disconnect.pdf.

Fukuyama, F. (1992). O Fim da História e o Último Homem. Lisboa: Gradiva.

Gallie, W. B. (1956). Essencially Contested Concepts. Proceedings of the Aristotelian Society New Series. Vol. 56, pp. 167-198. 
Han, B.-C. (2016). No Enxame. Reflexões sobre o digital. Trad. port. M. S. Pereira. Lisboa: Relógio D’Água.

Harari,Y. N. (2017). Homo Deus. História Breve do Amanhã. Trad. port. B. V. Amaral. Amadora: Elsinore.

Hunter, J. D. \& Owen IV, J. M. (2019). Prólogo. In Deneen, P. J. (2019). Porque está a falhar o liberalismo? Lisboa: Gradiva, 9-11.

Jünger, E. (2005). A Guerra como experiência interior. Trad. Port. A. C. e Silva. Lisboa: Ulisseia.

Kaczynski, T. (2010). Industrial Society and Its Future, Technological Slavery. Port Townsend: Feral House, pp. 38-120, available in: https:// www.washingtonpost.com/wp-srv/national/longterm/unabomber/ manifesto.text.htm.

Krastev, I. (2020). O Futuro por contar. Como a pandemia vai mudar o nosso mundo. Lisboa: Objectiva.

Locke, J. (2006). Ensaio sobre a verdadeira origem, extensão e fim do Governo Civil. Lisboa: Edições 70.

Mill, J. S. (2006). Sobre a Liberdade. Lisboa: Edições 70.

Pequenino, C. (2020). Maioria dos portugueses aceitam app para controlo da covid-19, diz Deco. Público, 7 de maio, disponível em: https://www.publico.pt/2020/05/07/tecnologia/noticia/maioriaportugueses-aceitam-app-controlo-covid19-deco-1915529.

Rorty, R. (1982). Nineteenth-Century Idealism and Twentieth-Century Textualism. Consequences of Pragmatism. Minneapolis: University of Minnesota Press, pp. 139-159.

Zakaria, F. (1997). The rise of illiberal democracy. Foreign Affairs, Vol. $76-$ N.o 6, pp. 22-43. 